\title{
JUAN BENET Y EL PENSAMIENTO MÍSTICO: MÁS ALLÁ DEL FATALISMO* JUAN BENET AND MYSTICAL THOUGHT: BEYOND FATALISM
}

\author{
JoRGE Machín LuCAS \\ University of Winnipeg
}

\begin{abstract}
RESUMEN
El presente artículo aborda la influencia mística en la obra literaria de Juan Benet. Es un aspecto crucial para entender el deseo de los protagonistas de sus novelas de volver al origen y de recomenzar la historia frente a la ruindad de un mundo en guerra y en destrucción. Es un anhelo, por supuesto, frustrado por la cruel realidad que les rodea de guerra, de ruinas y de destrucción física y moral. Esto se puede apreciar sobre todo en novelas tales como Volverás a Región, Una meditación, Un viaje de invierno o Saúl ante Samuel y en su libro de ensayos El ángel del señor abandona a Tobías.

PALABRAS ClAVE: Juan Benet, mística, intertextualidad, palimpsestos, postmodernidad.
\end{abstract}

\section{ABSTRACT}

This article is about mystical influence in the literary works of Juan Benet. This is a crucial aspect so as to understand the desire of the protagonists of his novels to return to the origin and to start over history against the evilness of a world at war and in destruction. Of course, it is a longing which has been frustrated by the cruel reality which surrounds them, with war, ruins, and physical and moral destruction. All this is obvious in such novels as Return to Region, A Meditation, A Winter Trip and Saul Facing Samuel and in his book of essays The Angel of the Lord Abandons Tobit.

KEY WORDS: Juan Benet, mysticism, intertextuality, palimpsests, postmodernity.

«El arte-decía Nietzsche-, no consiste en ampliar sus límites sino en buscar cada vez más límites» (Juan Benet, «El gran estilo», Cartografía, 128).

Es lugar común el entender la obra de Juan Benet (1927-1993), en todos sus géneros, pero sobre todo en el novelístico, en el cuentístico y en el ensayístico, como un gran manifiesto (meta)literario de fatalismo, de decadencia y de ruina, sobre todo en

\footnotetext{
* Recibido: 09-10-2018 / Aceptado: 09-05-2019.
} 
su célebre «ciclo novelístico de Región». En esa línea andan los estudios fundacionales y canónicos de Vicente Cabrera, de Malcolm Compitello, de Ricardo Gullón, de David Herzberger o de John B. Margenot III, entre tantos otros. No obstante, no se ha enunciado hasta el momento de manera sistemática que en los textos benetianos gravita, implícita y explícitamente, un quimérico deseo de vencer a ese cruel hado y de redimir y de salvar a la estirpe humana (Machín Lucas, 2015). Es un anhelo frustrado, por supuesto, por los prosaicos rigores de la cruel realidad de este mundo, compartido por toda una generación de escritores de la segunda mitad del siglo xx influidos por la mística.

El origen de este deseo benetiano de acabar con nuestra ruín historia de ambiciones y de belicismo y de renacer en otra Historia en mayúscula de igualdad y de justicia universal es doble. Por una parte, es puramente ontológico, una necesidad del ser de buscar explicaciones a su limitada esencia, percepción y temporalidad. Por otra, es intertextual, constituido por todo un mosaico de citas (248), como diría Julia Kristeva, o por un número notable de «hipotextos» o de textos preexistentes según Gérard Genette (5) que le han germinado y a los que él ha parodiado, algo típico de la cultura postmoderna (Lara Rallo, 138). Esta peculiar y autorreferencial apuesta de Benet empieza, así pues, desvirtuando y desmontando las piedras angulares del realismo, tan imperantes en la cultura y en la literatura españolas, para acabar divagando, con tono tan digresivo como admonitorio, acerca de las «zonas de sombras» de una realidad y de un ser que busca sus orígenes para recomponer su identidad, fragmentada por los conflictos que le ha tocado vivir, y para encontrar una vía nueva de comunión con todos los seres del mundo.

La crítica benetiana, prácticamente al completo, se cerró en ese límite heurístico que separa el pesimismo y el derrotismo de la nada más absoluta en las diégesis de sus novelas y cuentos y en las especulaciones de sus ensayos. No apreció la esperanza que, a pesar de estar llena de lógico escepticismo, a veces asoma nostálgica y emocionadamente entre sus enmarañados textos y que clama por atravesar ese umbral vital y epistemológico que hay entre la vida y la muerte, entre lo real y lo irreal, para descubrir una nada mística, plena espiritualmente. Este deseo, que subvierte los dictados del positivismo contra el que se alzó nuestro autor (Machín Lucas, 2001, páginas 23 y ss.), es propio de su forma mentis tan humanística como inconformista. Es el de volver a lo originario a través de la taumaturgia literaria y de un estilo trabajado y depurado para minorías altamente intelectuales con la intención de escapar de un destino aciago predeterminado: el de las luchas de poder en la historia, dominadas por su «elemento irracional y pasional» (Puerta de tierra, p. 177).

De allá dimana la única posibilidad de llegar a un mundo caracterizado por la justicia social y por la equidad cósmica. Como el mismo Benet menciona otra vez 
desde el espíritu iconoclasta y revisionista, predeconstructor y muchas veces nihilista de su maestro intelectual Nietzsche, si se hacen las cosas del revés, se tarda más, pero se encuentran más cosas y más nuevas (Del pozo, p. 67). Y esto es lo que -cómo no, infructuosamente- pretenderá hacer el narrador madrileño de Región: encontrar lo más novedoso en lo más viejo o la paz y la alegría más totales en el paraíso perdido, en la infancia reencontrada, en el útero materno, en la sopa primigenia, en el caldo primordial de la primera charca -más poética o filosófica que científica- que dio vida a su ser y a todos los entes de la creación.

Todos sus temas capitales en sus digresiones -el tiempo que nos domina, el espacio casi yermo que nos sustenta a duras penas, el destino inapelable que nos rige, la memoria impostora que selecciona y que adultera nuestros recuerdos, el conflicto y a la vez la dialéctica entre la razón y la pasión que nos castran como seres humanos plenos o la fatalidad que nos predestina, que nos envuelve y que nos asfixia, entre otros- se dirigen centrípetamente hacia el vórtice de una serie de reflexiones acerca de la necesidad de dar marcha atrás en la historia y de volver a lo más trascendente desde lo más inmanente, desde el examen solipsista de nuestra ipseidad. Allá, en ese microespacio de revelación, quiere Benet encontrar y abrir las puertas de un segundo origen para acabar con nuestra injusta historia y transformarla y reiniciarla con otra Historia de perfección una vez aprendidos y corregidos nuestros grandes errores, como pueden ser, por poner unos ejemplos, el egoísmo, el narcisismo, el abuso de la fuerza o la falta de solidaridad. Una idea que, por cierto, es más socialista que cristiana -aunque en su origen ambas se parecían-, sobre todo si se tiene en cuenta la cercanía que hubo en los últimos años del franquismo y a principios de la democracia entre el mismo Benet y esa ideología -sobre todo con el PSOE-, impulsado por su mentor y gran amigo, el ex falangista y Director General de Propaganda franquista, Dionisio Ridruejo, luego opositor declarado al régimen.

Esta idea tan «deconstructora» como «reconstructora», la de volver al inicio de los tiempos para reiniciar el programa de la historia con un nuevo hombre y una nueva raza perfeccionados, pretende asimismo ampliar nuestro conocimiento. Quiere ser una expansión gnoseológica de una realidad última que, para Benet, siempre se le escapa a la percepción y a la razón social, una que ha sido sin duda alguna consensuada para mantener el poder, las jerarquías, el sistema de clases sociales y, en general, todo el statu quo en nombre de un concepto muy relativo de orden. Según este novelista, «la ciencia es un estadio intermedio» para analizar el campo de lo real y del conocimiento y «la realidad aprendida es una realidad a medias y por tanto tan irreal como real» (El ángel, pp. 105-6). Por lo tanto, al volver al origen se podrá deconstruir esa ciencia y encontrar sus errores iniciales que no la permitieron haber avanzado ni más ni mejor en nuestra historia. Allí, además, se revelará un «sublime» largo tiempo esperado, sobre todo 
si entendemos este concepto como una expresión de lo inefable para Jean François Lyotard (pp. 78-81). Ese es el de una realidad ulterior que no podemos expresar con nuestro lenguaje convencional creado por nuestras limitadas mentes que solo pueden verbalizar lo poco que es perceptible para ellas. Solo se puede llegar a mínimamente a conceptualizar y a entender ese espacio-tiempo que está más allá de la lógica, de la materia y del sonido con «ese otro yo irracional y activo» que caracteriza la naturaleza de la indagación esotérica benetiana (Molina Ortega, p. 129).

Nique decir tienequeesteintento alquelelleva su inagotablesed deconocimiento, más que de comunicación, le emparenta con una nutrida tradición de autores que impone lo esotérico sobre lo exotérico, la búsqueda inmanente y trascendente sobre el examen de lo referencial y la semiosis sobre la mímesis. El listado sería inacabable, pero unos ejemplos de los más ilustres y cercanos a Benet serían las tradiciones místicas ibéricas y europeas de la Edad Media y del Renacimiento (la católica, la cabalística o la sufi, verbigracia), así como los románticos, los simbolistas, las vanguardias (con el surrealismo a la cabeza, sobre todo), la poesía de Juan Ramón Jiménez o de un Octavio Paz, la novela de Alejo Carpentier, la filosofía de María Zambrano o de Eugenio Trías, el cine de Vittorio de Sica (especialmente en Milagro en Milán) o de Andrei Tarkovski, o «la poesía del silencio» española de José Ángel Valente, de Antonio Gamoneda y de Clara Janés, entre otras fuentes. Todos estos movimientos o autores exploraron como él las «zonas de sombras» de la realidad y ampliaron las del conocimiento. Buscaron también el origen como evasión de la realidad y «como intento utópico de redención humana», tal y como vi hace pocos años en un artículo acerca de la obra de Gamoneda (Machín Lucas, p. 240). Todos ellos intuyeron espacios y tiempos interconectados en los que puede residir la gnosis que no son meramente cábalas literarias o teóricas, sino que pueden existir realmente más allá del alcance de nuestros sentidos y de nuestras lógicas.

El problema somos nosotros mismos y nuestras propias limitaciones perceptivas que nos han llevado a un pensamiento racional, cientifista o cartesiano insuficientes (de los que curiosamente Benet vivió como ingeniero de obras públicas), producidos por un consenso de mentes como las nuestras que tampoco han alcanzado su uso pleno. Estos pensamientos pretendidamente lógicos ya propuse en otro artículo que son también defendidos por sus sumos sacerdotes universitarios a veces de manera irracional y dogmática, como si constituyeran otro tipo de fe («Aproximaciones», p. 25), sobre todo cuando disertan acerca de las preguntas nunca contestadas sobre el origen de la vida o del universo. Es contra ellos contra los que cargará sus tintas el autor de Volverás a Región, un ingeniero que tan solo ejerció como tal, con precisión científica, en su vida civil. También manifesté acerca de la obra de Valente, con la que guarda en estos aspectos bastantes similitudes, que lo antirracional ayuda a lo racional, 
al llenar algunos de sus vacíos epistemológicos, para el progreso de una nueva historia premoderna en el nacimiento de la postmodernidad (José Ángel Valente, p. 294). Ese es el camino que va a seguir toda su obra literaria.

Aunque nunca estuviera entre sus lecturas preferidas, Benet no fue ajeno al pensamiento místico por sus proximidades con sus ideas acerca de la preponderancia de lo irracional sobre lo racional y de la importancia del examen inmanente y trascendente, sobre todo desde su noción de lo enigmático. Esta es para Ken Benson, en el discurso benetiano, al que vio desde una óptica estructuralista como un conflicto entre razón y espíritu (1989), «como una poética del enigma caracterizada fundamentalmente por lo que denominamos «la retórica del oxímoron», esto es, un imaginario alternativo al realista que se centra en la experiencia del mundo como enigma» (2004, p. 29). Esta noción de enigma oximorónico produce una síntesis desde su tesis y su antítesis constituidas por dos conceptos opuestos ilógicamente, las dos caras de una misma realidad, la afirmativa y la negativa. Esto es parecido a lo que defendió Félix de Azúa en el diálogo entre el texto de caja y los ladillos o acotaciones marginales en Un viaje de invierno, que puede ser oximorónica, paradójica o explicativa. En el fondo, la de Benet es una exploración más allá de lo racional similar a la de cualquier mística que se inscribe en esta era que algunos denominan como postmoderna en la que el avance y la saturación del capitalismo, del materialismo, del hedonismo y de lo tecnológico han desnaturalizado el mundo, su sociedad y su cultura (Jameson, p. 1) de lo espiritual.

Esta era postindustrial contra la que reacciona Benet recibe el espíritu de hiperproducción artística de la modernidad que vio sagazmente Walter Benjamin, el cual entendió que destruía el «aura» o la esencia inmaculada y única de la auténtica obra de arte (pp. 217-251). El intento de Benet va a ser el de recuperar ese «aura» no racional para devolvernos el origen perdido de la manera más prístina. Lipovetsky de hecho cree que lo postmoderno como cultura supone una ruptura declarada con el espíritu ilustrado (p. 118), lo que situaría al narrador de Región en una de las líneas epistemológicas más importantes de ese movimiento de análisis del presente histórico posterior a la Segunda Guerra Mundial y a la pérdida de fe en la razón que produjo su devastación. Benet mismo afirmaba lo siguiente sobre el pensamiento místico que se opone nostálgicamente a nuestras ruindad y miseria y que, según sus autores, nos lleva a una ignorancia más plena y placentera frente a la oximorónica nigra lux, a la nigra fons o al Deus absconditus:

Insoslayablemente situados en el tiempo trascendido, los místicos vinieron ya a hablar de la nostalgia humana por el tiempo absoluto -el tiempo del animal ocupado y encerrado en un instante presente-, en el que parece insinuarse la conclusión del drama de la razón por la destrucción de la temporalidad que le ha sido asignada (como si semejante temporalidad indisolublemente unida a aquella que la creó no la arrastrase en su caída) 
y la transustanciación del hombre -sin abandonar la figura humana- en esa cosa divina que en virtud de la omnisciencia reducirá el enigma por la vía opuesta, pero para alcanzar la misma meta, que la ignorancia (El ángel, pp. 134-135).

Yendo ya directamente hacia las obras de Benet, cabe decir que sus prosas y ensayos ratifican la hermenéutica de Adriana Minardi que propugna que sus espacios regionatos y sus ficciones actúan, respectivamente y en términos generales, como «condensados ideológicos» hacia el futuro (p. 198), como «matriz de conocimiento» del pasado y del presente, y como reflexión programática del futuro (p. 180). La misma crítica considera correctamente que la historia en Benet es un «agente de un futuro [...] operador ideológico de la utopía» («Hacer la historia», sin página). Ese concepto de utopía hacia el que se dirige Benet es posiblemente más amplio de lo que puede parecer y llega hacia un futuro que radica paradójicamente en un pasado ideal más allá de lo perceptible, hacia la antimateria y el silencio que demuestran que los conceptos de materia y de sonido que tenemos no son racionales ya que carecen de explicación a la totalidad de su esencia y de su estructura.

En este espacio-tiempo hay un conocimiento ulterior y tal vez superior a lo que reputamos como pretendidamente real. Aspira a ser esotérico, teleológico, el de la causa final, el del origen del ontos y del logos como nuevo futuro, el de otro destino que sustituya a este que nos devora. Está más allá de lo referencial, de la historia y de la memoria, en el olvido del mundo, en el supuesto origen presemiótico de una nueva palabra esencial, matriz. Va hacia más allá de la historia de los hechos registrados o por registrar por los historiadores, por los cronistas y por los voceros de los regímenes que nos gobiernan. Va hacia otros tipos de historias, tanto la que no podemos ver, más allá de lo real, como la que pudo haber sido y nunca fue. Va hacia un pasado elemental e idealizado también, como ya hemos visto, como catarsis personal y colectiva para purgar los errores cometidos y para, con la lección ya aprendida, no volverlos a cometer y poder vivir en paz.

Por consiguiente, estamos más allá del cronotopo de Región y de las afligidas y clamantes conciencias de sus personajes. A la cronología multiforme de la obra benetiana (un poliedro de tiempos, con tiempo cronológico, tiempo de la narración, tiempo de la historia, tiempo de la conciencia...) se añade un tiempo más lleno de claroscuros para los legos, para los no iniciados: el tiempo moral, el tiempo ético, el tiempo justiciero. Es un tiempo que vuelve al origen reclamando justicia universal. Este momento histórico aparece mostrado por Benet en algunas estampas, simulacros sin origen real de lo originario y de solución a nuestros males, si seguimos las ideas de Baudrillard (pp. 9-10). Benet entiende que esas estampas son como brillantes, misteriosas y fugaces imágenes estáticas, una especie de descripciones congeladas y 
cerradas en sí mismas, el momento en que se inmoviliza y se manifiesta «un cruce o una coincidencia entre líneas argumentales» (1999, p. 151).

Aunque el propósito de tales estampas es revelar un gran misterio pararracional y mostrarnos un nuevo inicio, finalmente estas no tienen una unidad semiótica sino infinitas interpretaciones, tantas como puedan darle el mismo autor y cada lector. Esa es la gran paradoja del acto literario y del saber en general: todo intento de ir hacia una fórmula o hacia una solución global a nuestros males es vano en la realidad en que vivimos. Estamos en el debate eterno entre lo ideal y lo real y en lo que Ihab Hassan denomina como «indetermanencia», la suma de indeterminación e inmanencia (p. 91), a saber, una penetración en nuestras fragmentadas conciencias, en nuestra interioridad, para explicarlas, para reconstruirlas y para intentar trascenderlas hacia un punto indeterminado ya que todavía nadie conoce el porqué de las cosas ni para qué las hacemos. Toda ciencia está hecha tan solo con la ilusión de llegar al conocimiento y al bien supremo sin saber qué forma ni qué contenidos pueden tener. Estamos, en definitiva, ante la muy postmoderna noción de «incertidumbre», lógica y existencial, tan cacareada por Benet como por sus críticos.

Continuamos en el espectro de lo ideal, que es el que nutre y da sentido a la literatura y a las ideas humanas. Conviene dejar sentado que esa búsqueda de los límites, no solo del bosque de Mantua (que no se atreven ni a cruzar los habitantes regionatos de sus inmediaciones en Herrumbrosas lanzas -p. 417-) sino también de la realidad, de la materia, del sonido, de la razón, del espacio, del tiempo y de la vida, es de orden trascendente (Un viaje de invierno, p. 248). De allá se podría originar un nuevo mundo más perfecto en oposición al regionato locus eremus (Machín Lucas, 2009, p. 161), que es controlado manu militari e inapelablemente por el anciano cústode de una razón social inmemorial y principal represor y agresor de la pasión individual, el fiero Numa, tanto como por unas fuerzas impersonales que controlan, desde el bosque de Mantua, las vidas de todos los regionatos.

Esta se representa como una vuelta al origen, pero en realidad es una ida por primera vez, más implícitamente intuida o presentida que explícitamente expresada, pero que subyace en el agónico subconsciente de Benet y de los narradores que crea. Esta idea del retorno, que en la diégesis principal de sus novelas regionatas se presenta como una fracasada marcha hacia la muerte, procede intertextualmente del filósofo Nietzsche (el eterno retorno de «la rueda del ser» que nos ha de llevar evolucionando a un futuro mejor y a la eternidad -Nietzsche, 2009, p. 261-) y del historiador clásico Jenofonte (el retorno a Grecia de los mercenarios griegos de Ciro, que lucharon contra su hermano Artajerjes II, el Rey de Persia, acaudillados tras la muerte del primero por 
Clearco y, tras el óbito de este, finalmente por el mismo autor de la obra). En ambos casos se hace una parodia de esos «hipotextos».

Vamos ya a comentar ciertos extractos que confirman la tesis que se defiende en este artículo de que Benet tenía un deseo de encontrar soluciones trascendentes a la miseria moral de este mundo más allá del pesimismo y del fatalismo en el que se ha detenido la crítica hasta ahora. Por ejemplo, en la que muchos consideran como su obra maestra, su primera novela Volverás a Región, se habla de esa vuelta al origen para comenzar una nueva historia con los errores aprendidos. Eso sucede durante el diálogo, que en realidad se convierte en dos monólogos ya que sus obsesivos portavoces, inmersos en la vorágine de sus rememoraciones, apenas se escuchan. Es el que hay entre Marré Gamallo y el doctor Daniel Sebastián. Ambos personajes, con su falta de decorum, es decir, con la ausencia de diferencias de clase social o culturales en los estilos de sus enunciaciones, son portavoces de la ideología benetiana. Se dice que para la «reanudación del ciclo crónico» existe un «regressus ad uterum para borrar los errores y descarríos de la edad presente y preparar el nacimiento de una nueva raza» con respecto a un viaje anual que tiene «el valor de un rito, el misterio de una fe y el sentido de una confirmación» (p. 154). Solo la muerte, en el turbio mundo de Región, de congelada temporalidad y de inapelable destino hacia el fracaso custodiado por el Numa, podría abrir sus puertas.

En su segunda novela, Una meditación, el viaje de la lúbrica Leo Titelácer y de Carlos Bonaval a la cueva de la Mansurra en las montañas del Hurd, que a él le puede servir para superar la frustración de no haber consumado otro viaje que, años antes, hizo con otra mujer, tiene mucho de búsqueda originaria en los límites entre la vida y la muerte, entre el eros y el tánatos, entre un presente estático y un futuro que mira hacia un pasado que nunca existió, y entre lo artificial y lo natural. Mientras los amantes se encaminan a consumar su pasión amorosa, el reloj de Cayetano Corral se acciona hacia un tiempo de destrucción que bien puede ser la antesala de un nuevo y esperanzador origen. Este tiempo es solo comprensible mediante una intuición que está más allá de nuestros sentidos y que será posterior al final de la diégesis de la novela y tan solo reconstruible por el lector en su mente tras su decodificación textual. Antes de que esto suceda, se expresa lo siguiente:

Y eso era en definitiva lo más desconcertante, lo que quizá mantenía en el inconcluso y silenciado reloj un imperceptible germen de animación que se alimentaba de una sorpresa que no había sido explicada para conservarse en una esperanza que no había sido desmentida (p. 80).

Lógicamente, ese «germen de animación», esa «sorpresa» y esa «esperanza» que no han sido desmentidos por una razón insuficiente epistemológicamente aluden 
a esa posibilidad de encontrar la justicia histórica más allá de la muerte después del arrasamiento cronológico y telúrico de la zona al final de la diégesis.

En su tercera novela, Un viaje de invierno, la memoria como estructura genética «suprapersonal», que disipa y niega todo lo vivido, trata de retrotraerse «a una edad sin fechas, la iluminada jornada de un ayer envuelto en ámbar temporal sin movimientos ni enigmas, sin evolución ni crecimiento ni estaciones ni sonidos...» (p. 206). Este pasado congelado es el del inicio del cosmos justo antes de la gran explosión que activará su peculiar cronología hacia la eternidad como se ha visto en los párrafos anteriormente citados. En una de sus últimas novelas, titulada Saúl ante Samuel, tal vez la mejor en cuanto a su síntesis y expurgo de temas anteriormente tratados en otras obras, a su calidad estilística, a su originalidad y a su profundidad de pensamiento y a la variedad y a la concentración de temas argumentales abordados, hay un beso de despedida que deja a sus protagonistas «en esa vertiente del limbo que mira hacia la devastación y la sordera...» (p. 315), «...hacia una corriente del tiempo paralela y opuesta a la cotidiana» separadas tenuemente y al otro lado de la mítica laguna Estigia, la de la muerte (p. 370). Es sin lugar a dudas una referencia a ese tiempo invertido, opuesto al cronológico convencional de las agujas del reloj, que nos llevará a ese pasado tras la destrucción de nuestro mundo («la devastación») y tras el silencio («la sordera») de donde broten el primer fonema y la palabra matriz de una nueva era. Finalmente, en uno de sus libros de ensayos más conocido, El ángel del señor abandona a Tobías, Benet afirma que, en última instancia y en una lectura profunda, el suyo

...es el sueño del silencio, de la carencia de la palabra, del estatuto -por decirlo de manera etimológica- infantil de la naturaleza, del largo momento preauroral que no sacude su sopor aun cuando las primeras voces articuladas anuncian el despertar de un nuevo día (p. 70).

Es curioso que un autor tan prolijo en palabras, en cultismos, en tecnicismos, en una gramática abigarrada, en una sintaxis laberíntica, esteticista y poética, de frases larguísimas, de subordinadas y de paréntesis, todo ello de ancestros proustiano y faulkneriano, aspire a cancelar nuestro sistema lingüístico por completo. Tal vez, como buen científico que era, supiera que cuanto más se alarga un objeto hasta el infinito más se difumina hasta llegar a aparentar su desaparición. Por tanto, a falta de un nuevo lenguaje más perfecto que nos lleve al bien y a la justicia, para desvelar ese misterio él propone la máxima cantidad de palabras y de conceptos para definir el máximo posible de aristas de la poliédrica realidad que vemos y de la que no vemos.

Esta es, en conclusión, la puesta en escena literaria por parte de Benet de una expansión del campo de lo real y de una vuelta al origen para reconstruir un orden mítico y místico frente a una injusta y soberbia razón social con una esperanza, llena de 
mucho escepticismo, de llegar a una justicia absoluta y eterna. No obstante, su único intento de crear una nueva «realidad indefinible e infinita» (La inspiración y el estilo, p. 223) más que a través de lo esotérico o de lo argumental se redujo al valor taumatúrgico de sus digresiones o especulaciones pseudofilosóficas, de sus palimpsestos más notables (Friedrich Nietzsche, William Faulkner, Marcel Proust, Euclides da Cunha, Sir James George Frazer, Henry James, la historiografía clásica y la Biblia...) y de su propio estilo, que Fraser conecta con procesos mentales que están más allá del ámbito de la razón (p. 68). El autor del mundo de Región dice lo siguiente al respecto: «¿Qué barreras pueden prevalecer contra un hombre que en lo sucesivo será capaz de inventar la realidad?» (Ibid.).

Este ingeniero de la escritura debió detallar más concretamente que un estilo solemne, decoroso e intertextual más que crearla nos puede conducir hacia ella aunque sea tan solo en nuestra imaginación. Final y lamentablemente, el pesimismo y pragmatismo de la experiencia benetiana ante los desmanes y horrores de la historia y ante su conocimiento sobre la Guerra Civil española hace que ese utópico sueño de redención colapse ante la proterva realidad de las luchas de egos y de los conflictos humanos. Como dice muy sabiamente en Saúl ante Samuel: «El tiempo se yergue a la voz de la justicia, pero sólo se incorpora ante la visión de la venganza» (p. 385). La justicia, por ende, es un ideal por el que se ha de luchar y sus absolutos acaso solo se puedan encontrar en el idealismo del arte que nos transporta a otros mundos. En este mundo en que hemos nacido, por el contrario, desde la experiencia y desde las voces oraculares de la historia, el recurso más rápido y contundente para atajar la violencia sigue siendo la violencia individual o colectivo-militar mucho más que el diálogo. Benet nunca cruzó los límites hacia la nueva realidad, aunque desde el umbral, clamó por que los traspasáramos algún día con la evolución de una nueva ciencia para investigar y desarrollar mucho más: la de la mística.

\section{BiBLIOGRAFÍA}

Baudrillard, J., Cultura y simulacro, Antoni Vicens y Pedro Rovira (trad.), Barcelona, Kairós, 2012.

BENET, J., Una meditación, Barcelona, Seix Barral, 1970. , Puerta de tierra, Barcelona, Seix Barral, 1970.

, El ángel del señor abandona a Tobias, Barcelona, La Gaya Ciencia, 1976.

, Del pozo y del Numa (Un ensayo y una leyenda), Barcelona, La Gaya Ciencia, 1978. , Un viaje de invierno, Diego Martínez Torrón (ed.), Madrid, Cátedra, 1989. , Saúl ante Samuel, John B. Margenot III (ed.), Madrid, Cátedra, 1994. 
, Volverás a Región, Víctor García de la Concha (coment.), Barcelona, Destino, 1996.

, Cartografía personal, Valladolid, Cuatro ediciones, 1997.

, Herrumbrosas lanzas, Madrid, Santillana - Alfaguara, 1998.

, La inspiración y el estilo, Madrid, Alfaguara, 1999.

Benjamin, W., «The Work of Art in the Age of Mechanical Reproduction», en Hannah Arendt (ed.), Illuminations: Essays and Reflections, New York, Schocken Books, 1968, pp. 217-251.

BENSON, K., Razón y espíritu. Análisis de la dualidad subyacente en el discurso narrativo de Juan Benet, Stockholm, Stockholms Universitet, Romanska Institutionen, 1989. , Fenomenología del enigma. Juan Benet y el pensamiento literario postestructuralista, Amsterdam-New York, NY, Rodopi, 2004.

Cabrera, V., Juan Benet, Boston, G. K. Hall, Twayne World Author Series, Twayne Publishers, 1983.

Compitello, M. A., Ordering the Evidence: «Volverás a Región» and the Civil War Fiction, Barcelona, Biblioteca Universitaria Puvill, 1983.

De AzúA, F., «El texto invisible. Juan Benet: Un viaje de invierno», Cuadernos de la Gaya Ciencia, 1 (mayo de 1975), pp. 7-21. (Reimpreso en Vernon, pp. 147-157).

Fraser, B., Understanding Juan Benet. New Perspectives, Malcolm Alan Compitello (prólogo), Columbia, SC, The University of South Carolina Press, 2013.

Genette, G., Palimpsests: Literature in the Second Degree, Channa Newman and Claude Doubinsky (trad.), Gerald Prince (prólogo), Lincoln, Ne \& London, University of Nebraska Press, 1997.

Gullón, R., «Una región laberíntica que bien pudiera llamarse España», Ínsula, 319 (junio de 1973), pp. 2 y 10.

Hassan, I. H., The Postmodern Turn: Essays in Postmodern Theory and Culture, Columbus, Ohio State University Press, 1987.

Herzberger, D. K., The Novelistic World of Juan Benet, Clear Creek, IN, The American Hispanist, 1976.

Jameson, F., Postmodernism, or, The Cultural Logic of Late Capitalism, Durham, Duke University Press, 1991.

Jenofonte. Anábasis. La expedición de los diez mil, José Luis Vidal (intr.) y Ángel SánchezRivero (trad.), Barcelona, Planeta, 1993.

Kristeva, J., El texto de la novela, Jordi Llovet (trad.), Barcelona, Lumen, 1981.

Lara Rallo, C., Las voces y los ecos. Perspectivas sobre la intertextualidad, Málaga, Analecta Malacitana, 2007.

Lipovetsky, G., La era del vacío, Barcelona, Anagrama, 2010.

Lyotard, J. F., The Postmodern Condition, Geoff Bennington and Brian Massumi (trad.), Minneapolis, University of Minnesota Press, 1993. 
Machín LuCAS, J., «Juan Benet al trasluz: palimpsestos subversivos en Región», Cuadernos hispanoamericanos, 609 (marzo de 2001), pp. 19-28.

, El primer Juan Benet (1965-1972): La forja de un estilo novelístico, Saarbrücken, VDM Verlag, 2009.

, «La poética de Antonio Gamoneda: el referente esotérico», Lectura y signo, 4 (2009), pp. 239-71.

, José Ángel Valente y la intertextualidad mística postmoderna: del presente agónico al presente eterno, Santiago de Compostela, Universidade de Santiago de Compostela, 2010.

, «Aproximaciones (supra), (intra) y (extra)literarias a lo irracional en las letras hispanas de los siglos xx y xxI: un esbozo de teoría del caos», La nueva literatura hispánica, 16 (2012), pp. 9-54.

, «Los palimpsestos de Jenofonte, de la mística y de Nietzsche en la narrativa de Juan Benet», Ínsula, 825 (año Lxx), (septiembre 2015), pp. 8-11.

Margenot III, J. B., Zonas y sombras: aproximaciones a «Región» de Juan Benet, Madrid, Pliegos, 1991.

MinARDI, A., «Hacer la Historia: el sentido de práctica discursiva en Qué fue la guerra civil, de Juan Benet. La construcción del intelectual después de Franco», 2006. Disponible en www.ucm.es/info/especulo/numero32/hacerhis.html [fecha de consulta 05-10-2018].

, «Las tramas de la historia entre la memoria, la utopía y la guerra: Herrumbrosas lanzas de Juan Benet y El laberinto mágico de Max Aub», en Actas del xvi Congreso de la Asociación Internacional de Hispanistas. Nuevos caminos del hispanismo... 6. Historia y politica, Pierre Civil y Françoise Crémoux (eds.), Madrid y Frankfurt am Main: Iberoamericana Vervuert, 2010, pp. 192-201.

, Historia, memoria, discurso. Variaciones sobre algunos ensayos benetianos, Madrid, Pliegos, 2012.

Molina Ortega, A. M., Las otras regiones de Juan Benet, Cáceres, Universidad de Extremadura, 2007.

Nietzsche, F., Así habló Zaratustra. Un libro para todos y para nadie, José Rafael Hernández Arias (trad. y notas), en Nietzsche, Vol. II, Madrid, Gredos, 2009, pp. 11-380. 